\title{
Prediction of Rock Burst, Squeezing and Support Design using Three-Dimensional and Conventional Methods along Headrace Tunnel in Balephi, Nepal
}

\author{
Nishkarsha Dawadi ${ }^{\# 1}$ \\ ${ }^{\# 1}$ Student, M.S. in Geotechnical Engineering, Institute of \\ Engineering, Tribhuvan University \\ Pulchowk, Lalitpur, Nepal
}

\author{
Akkal Bahadur Singh ${ }^{* 2}$ \\ ${ }^{* 2}$ Professor, Department of Civil Engineering, Institute of \\ Engineering, Tribhuvan University \\ Pulchowk, Lalitpur, Nepal
}

\begin{abstract}
The prediction of rock burst and squeezing along the headrace tunnel of Upper Balephi ' $A$ ' hydropower project is presented in this paper. The rock mass classification along the headrace tunnel at various sections are presented. The assessment of potential rock burst is carried out using methods suggested by various researches and squeezing is predicted using empirical and semi-empirical methods. The support system design of a section in the headrace tunnel and at its junction with an underground vertical surge shaft is also presented. The support system suggested by the empirical RMR and Q-value method is compared with the support system suggested by convergence confinement method and safety factor is checked for the most demanding support system using numerical modeling. Three-dimensional modeling is carried out in sections where the longitudinal homogeneity of stress distribution is disturbed and plain strain condition is not valid. The finite element modeling is done using Phase $^{2}$ for two-dimensional modeling and GTS NX for three-dimensional modeling at the junction of main tunnel with the surge shaft.
\end{abstract}

Keywords - Tunnel, Rock Mass Classification, Surge Shaft, Tunnel Support, Rock Burst, Squeezing, Empirical Method, Convergence confinement method, Numerical modelling, ThreeDimensional modelling, Phase ${ }^{2}$, GTS NX, Tunnel Junction

\section{INTRODUCTION}

Tunnel are underground structure generally used as the shortest mean of conveyance. In Nepal, due to the diverse geography, land form changes within short reach and in case of hydropower, higher head can be achieved in short distances. Thus, tunnel is conveniently used over canal for conveying water to the powerhouse from the intake. While underground excavation itself is a very challenging construction, it also brings along various geological hazards like squeezing and rock burst. So, proper analysis should be made before designing a support system in tunnel. On the other hand, in certain sections in a tunnel like connection with an adit, tunnel bends or underground surge shaft, plain strain condition can no longer be assumed as the longitudinal homogeneity of stress distribution around the tunnel is disturbed and the stress distribution becomes three-dimensional. Only threedimensional analysis can suggest accurately, the support system needed in such junctions.

The aim of this paper is to analyse the rock mass properties, to predict rock burst and squeezing along the headrace tunnel of Upper Balephi ' $\mathrm{A}$ ' hydropower project and to find the required support system at certain sections of major importance. Upper Balephi 'A' is a hydropower project located in Sindhupalchowk district in Nepal, with an installed capacity of 36MW. It has a net head of $197.24 \mathrm{~m}$ and design discharge of $21.3 \mathrm{~m} 3 / \mathrm{s}$ [1].

TABLE I: ROCK MASS PARAMETERS [1]
\begin{tabular}{|l|l|l|l|}
\hline $\begin{array}{l}\text { Chainage } \\
(\mathbf{m})\end{array}$ & Overburden (m) & RMR & Q-value \\
\hline $0+600$ & 155 & 70 & 10 \\
\hline $1+400$ & 205 & 55 & 3 \\
\hline $2+000$ & 590 & 40 & 0.8 \\
\hline $2+500$ & 345 & 30 & 0.066 \\
\hline $3+200$ & 145 & 25 & 0.003 \\
\hline $\begin{array}{l}1+460 \\
\text { (Tunnel Bend) }\end{array}$ & 239 & 55 & 3 \\
\hline $\begin{array}{l}3+185 \\
\text { (Adit Junction) }\end{array}$ & 170 & 25 & 0.003 \\
\hline $\begin{array}{l}4+520 \\
\text { (Surge Shaft) }\end{array}$ & 103 & 45 & 1 \\
\hline
\end{tabular}

The rock cover, uniaxial compressive strength (UCS), Geological strength index (GSI), Rock Mass Rating (RMR) and Q-value of some sections in the alignment of the Headrace tunnel is given in Table I.

Prediction of ground condition, i.e. Rock Burst and Squeezing is made for first five sections shown in Table I along the tunnel alignment. The section at chainage $2+000$ has considerably high overburden, so the design of support system at this section is presented in this paper. Also, the design of connection with the Surge Shaft using threedimensional modelling is presented in this paper.

\section{PREDICTION OF ROCK BURST}

Approaches suggested by various researchers were used to access potential rock burst [2] [3]. By making detailed studies for the stability analysis in different tunnels in South Africa, Hoek and Brown suggested a method to access rock burst potential, by using the ratio of uniaxial compressive strength $\left(\sigma_{c}\right)$ and tangential stress $\left(\sigma_{\Theta}\right)[2]$. Grimstad and Barton also 
made a relation by using stress measurements and rock mass strength, which supports the finding of Hoek and Brown [3]. They also used the ratio of uniaxial compressive strength $\left(\sigma_{c}\right)$ and tangential stress $\left(\sigma_{\Theta}\right)$ to describe various conditions of rock bursting potential. These criteria are given in Table II. The tangential stresses in above relations are calculated using the relation proposed by Hoek and Brown [2]. For estimation of the tangential stresses for roof $\left(\sigma_{\Theta \mathrm{r}}\right)$ and walls $\left(\sigma_{\Theta \mathrm{w}}\right)$ in massive rocks, Hoek and Brown gave the following equations according to the excavation shapes.

$$
\begin{gathered}
\sigma_{\theta \mathrm{r}}=(\mathrm{A} \times \mathrm{k}-1) \sigma_{z} \\
\sigma_{\theta \mathrm{w}}=(\mathrm{B}-\mathrm{k}) \sigma_{z}
\end{gathered}
$$

where $\sigma_{\Theta}$ is for tangential stress ( $\sigma_{\Theta \mathrm{r}}$ for roof and $\sigma_{\Theta \mathrm{w}}$ for wall), $\mathrm{k}$ is the horizontal/vertical stress ratio, $\sigma_{\mathrm{z}}$ is the vertical stress and $\mathrm{A}, \mathrm{B}$ are the excavation geometry factors. The value of $\mathrm{A}$ and B in above equations [2] depend on the shape of the cross section of the tunnel which are given in Figure I. The field stresses calculated for various sections are given in Table III. The detail results on prediction of rock burst based on criteria defined by these researchers are given in Table IV and V.

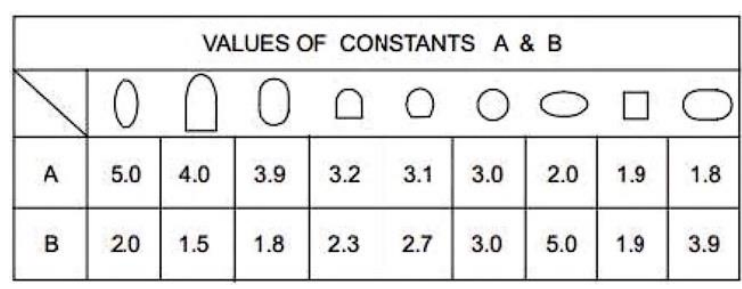

Figure I: VALUE OF A AND B FOR VARIOUS SHAPES OF TUNNEL OPENINGS [2]

TABLE II: CRITERIA DEFINED BY DIFFERENT RESEARCHERS FOR ROCK BURST

\begin{tabular}{|c|c|c|c|c|c|c|c|c|c|c|}
\hline Chainage & $\begin{array}{l}\text { Maximum } \\
\text { rock } \\
\text { cover }(\mathbf{H}) \\
\text { in } \mathbf{m}\end{array}$ & $\begin{array}{l}\text { Poisson } \\
\text { Ratio }\end{array}$ & $\begin{array}{l}\text { Tectonic } \\
\text { stress, } \\
\text { MPa }\end{array}$ & $\begin{array}{l}\text { Unit } \\
\text { Weight, } \\
\text { MN/m3 }\end{array}$ & $\begin{array}{l}\text { Vertical } \\
\text { Stress, } \\
\text { MPa }\end{array}$ & $\begin{array}{l}\text { Horizontal } \\
\text { Stress, } \\
\text { MPa }\end{array}$ & $\mathbf{K}$ & $\sigma_{c}$ & $\sigma \theta r$ & $\sigma \Theta w$ \\
\hline $0+600$ & 155.00 & 0.10 & 3.50 & 0.027 & 4.19 & 3.97 & 0.70 & 50 & 5.19 & 6.70 \\
\hline $1+400$ & 205.00 & 0.10 & 3.50 & 0.027 & 5.54 & 4.12 & 0.60 & 50 & 5.09 & 9.41 \\
\hline $2+000$ & 590.00 & 0.10 & 3.50 & 0.027 & 15.93 & 5.27 & 0.40 & 40 & 4.46 & 30.27 \\
\hline $2+500$ & 345.00 & 0.10 & 3.50 & 0.026 & 8.97 & 4.50 & 0.40 & 40 & 2.51 & 17.04 \\
\hline $3+200$ & 145.00 & 0.10 & 3.50 & 0.026 & 3.77 & 3.92 & 0.70 & 30 & 4.67 & 6.03 \\
\hline
\end{tabular}

\begin{tabular}{|l|l|l|l|}
\hline \multicolumn{2}{|c|}{ Hoek and Brown [2] } & \multicolumn{2}{c|}{ Grimstad and Barton [3] } \\
\hline Ratio $\left(\sigma_{\mathrm{c}} / \boldsymbol{\sigma}_{\Theta}\right)$ & Description & Ratio $\left(\sigma_{\mathrm{c}} / \boldsymbol{\sigma}_{\Theta}\right)$ & Description \\
\hline$\sigma_{\mathrm{c}} / \sigma_{\Theta}>7$ & Stable & $\sigma_{\mathrm{c}} / \sigma_{\Theta}>100$ & Low stress, near surface, open joints \\
\hline$\sigma_{\mathrm{c}} / \sigma_{\Theta}=3.5$ & Minor sidewall spalling & $\sigma_{\mathrm{c}} / \sigma_{\Theta}=3-100$ & Medium stress, favorable stress conditions \\
\hline$\sigma_{\mathrm{c}} / \sigma_{\Theta}=2$ & Severe spalling & $\sigma_{c} / \sigma_{\Theta}=2-3$ & $\begin{array}{l}\text { High stress, usually favorable to stability, maybe } \\
\text { unfavorable to wall stability }\end{array}$ \\
\hline$\sigma_{\mathrm{c}} / \sigma_{\Theta}=1.7$ & Heavy support required & $\sigma_{\mathrm{c}} / \sigma_{\Theta}=1.5-2$ & Moderate slabbing after one hour \\
\hline$\sigma_{\mathrm{c}} / \sigma_{\Theta}<1.4$ & Severe rock burst problem & $\sigma_{c} / \sigma_{\Theta}=1-1.5$ & Slabbing and rock burst after minutes in massive rocks \\
\hline & & $\sigma_{c} / \sigma_{\Theta}<1$ & Heavy rock burst and immediate rock deformation \\
\hline
\end{tabular}

\begin{tabular}{|c|c|c|c|c|}
\hline \multirow{2}{*}{ Chainage } & \multicolumn{2}{|r|}{ For Roof } & \multicolumn{2}{|r|}{ For Wall } \\
\hline & $\sigma_{\mathrm{c}} / \sigma_{\Theta \mathrm{r}}$ & Prediction & $\sigma_{c} / \sigma_{\Theta w}$ & Prediction \\
\hline $0+600$ & 9.64 & Stable & 7.47 & Stable \\
\hline $1+400$ & 9.82 & Stable & 5.31 & Minor Sidewall Spalling \\
\hline $2+000$ & 8.97 & Stable & 1.32 & Heavy support required \\
\hline $2+500$ & 15.93 & Stable & 2.35 & Minor Sidewall Spalling \\
\hline $3+200$ & 6.42 & Minor sidewall spalling & 4.97 & Minor Sidewall Spalling \\
\hline
\end{tabular}

TABLE IV: RESUltS OF Rock BURST ASSESSMENT USING HOEK AND BROWN'S APPROACH 
TABLE V: RESUltS OF ROCK BURST ASSESSMENT USING GRIMSTAD AND BARTON'S APPROACH

\begin{tabular}{|l|l|l|l|l|}
\hline \multirow{2}{*}{ Chainage } & \multicolumn{3}{|c|}{ For Roof } & \multicolumn{2}{c}{ For Wall } \\
\cline { 2 - 5 } & $\boldsymbol{\sigma c} / \boldsymbol{\sigma} \boldsymbol{*}$ & Prediction & $\boldsymbol{\sigma} / \boldsymbol{\sigma \theta w}$ & Prediction \\
\hline $0+600$ & 9.64 & Medium Stress, favorable stress condition & 7.47 & Medium Stress, favorable stress condition \\
\hline $1+400$ & 9.82 & Medium Stress, favorable stress condition & 5.31 & Medium Stress, favorable stress condition \\
\hline $2+000$ & 8.97 & Medium Stress, favorable stress condition & 1.32 & $\begin{array}{l}\text { Slabbing and rock burst after minutes in massive } \\
\text { rocks }\end{array}$ \\
\hline $2+500$ & 15.93 & Medium Stress, favorable stress condition & 2.35 & $\begin{array}{l}\text { High stress, usually favorable to stability, maybe } \\
\text { unfavorable to wall stability }\end{array}$ \\
\hline $3+200$ & 6.42 & Medium Stress, favorable stress condition & 4.97 & Medium Stress, favorable stress condition \\
\hline
\end{tabular}

\section{PREDiCTION OF SQUEEZING}

Assessment of potential squeezing was made using tunneling quality index values. Empirical and Semi-empirical methods were used. By using Barton's Q-value and overburden in the tunnel, Singh et al. [4] in 1992 developed an empirical equation to predict squeezing in rocks. Goel et al. [5] also developed an equation based on rock mass number (Q-value for SRF = 1), overburden and width of the tunnel. The suggested equations and squeezing conditions by various methods are given below in Table VI.

TABLE VI: SQueEZING CONDITIONS AS PER VARIOUS EMPIRICAL METHOdS [4] [5]

\begin{tabular}{|l|l|l|}
\hline Method & $\begin{array}{l}\text { Squeezing } \\
\text { condition }\end{array}$ & $\begin{array}{l}\text { Non-squeezing } \\
\text { condition }\end{array}$ \\
\hline $\begin{array}{l}\text { Singh et } \\
\begin{array}{l}\text { al. } \\
(\mathbf{1 9 9 2})\end{array}\end{array}$ & $\begin{array}{l}\mathrm{H}>350 \mathrm{Q}^{1 / 3} \\
\text { meters }\end{array}$ & $\begin{array}{l}\mathrm{H}<350 \mathrm{Q}^{1 / 3} \\
\text { meters }\end{array}$ \\
\hline $\begin{array}{l}\text { Goel } \\
\text { et al. } \\
\mathbf{( 1 9 9 4 )}\end{array}$ & $\begin{array}{l}\mathrm{H}>\left(^{275} \mathrm{~N}^{0.33}\right) \mathrm{B}^{-0.1} \\
\text { meters }\end{array}$ & $\begin{array}{l}\mathrm{H}>\left(275 \mathrm{~N}^{0.33}\right. \\
\text { meters }\end{array}$ \\
\hline
\end{tabular}

A semi-empirical approach suggested by Hoek and Marinos 2000 [6] was also used to check squeezing in tunnel. It is based on the ratio of uniaxial compressive strength and the in-situ stress. They used Sakurai 1983 [7] approach to determine the relationship between $\sigma_{\mathrm{cm}} / \mathrm{p}_{\mathrm{o}}$ and the percentage strain of the tunnel. Hoek and Marinos [6] also suggested the classifications of squeezing severity based on the strain percentage. There are five classes of squeezing problems from few support problems to extreme squeezing problems i.e.; from $\mathrm{A}$ to $\mathrm{E}$. The ranges of these classes are shown in Figure II.

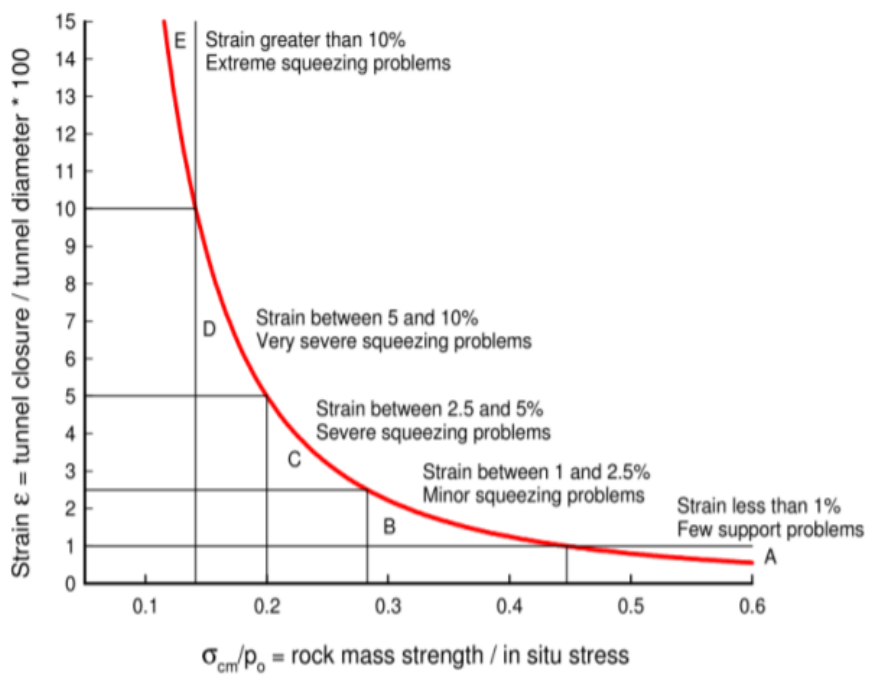

FIGURE II: APPROXIMATE RELATIONSHIP AND THE DEGREE OF DIFFICULTY ASSOCIATED WITH TUNNELING THROUGH SQUEEZING IN ROCK IN CASE OF UNSUPPORTED TUNNEL [6]

\begin{tabular}{|c|c|c|c|c|c|c|c|c|}
\hline \multirow{3}{*}{$\begin{array}{l}\text { Chainage } \\
\text { (m) }\end{array}$} & \multirow{3}{*}{ Overburden } & \multicolumn{7}{|c|}{ ASSESSMENT OF SQUEEZIN } \\
\hline & & & & $\mathrm{N} \quad$ value & $\begin{array}{l}\text { Singh } \\
1992\end{array}$ & $\begin{array}{l}\text { Goel } \\
1994\end{array}$ & \multicolumn{2}{|c|}{ Check } \\
\hline & & RMIR & Value & SRF $=1$ & $350 Q^{1 / 3}$ & $\begin{array}{c}275 \mathbf{N}^{0.33} \\
\times \mathbf{B}^{-0.1} \\
\end{array}$ & Singh & Goel \\
\hline $0+600$ & 155 & 70 & 10 & 700 & 754.05 & 511.83 & Non-Squeezing & Non-Squeezing \\
\hline $0+1400$ & 205 & 55 & 3 & 165 & 504.78 & 344.01 & Non-Squeezing & Non-Squeezing \\
\hline $0+2000$ & 590 & 40 & 0.8 & 32 & 324.91 & 222.40 & Squeezing & Squeezing \\
\hline $0+2500$ & 345 & 30 & 0.066 & 1.98 & 141.44 & 97.62 & Squeezing & Squeezing \\
\hline $0+3200$ & 145 & 25 & 0.003 & 0.075 & 50.47 & 35.20 & Squeezing & Squeezing \\
\hline
\end{tabular}


TABle VIII: Results of Assessment of SQUEEZING Using SEMI-EMPIRICAL MeTHOD By HoEK AND MARINOS (2000)

\begin{tabular}{|l|l|l|l|l|l|l|}
\multicolumn{2}{l|}{ TABLE VIII: RESULTS OF ASSESSMENT OF SQUEEZING USING SEMI-EMPIRICAL METHOD BY HOEK AND MARINOS (2000) } \\
\hline Chainage & Overburden & UCS & $\begin{array}{l}\text { Tunnel } \\
\text { Diameter } \\
(\mathbf{m})\end{array}$ & $\begin{array}{l}\text { Tunnel } \\
\text { Closure (m) }\end{array}$ & $\begin{array}{l}\text { Strain without } \\
\text { support, } \boldsymbol{\varepsilon}\end{array}$ & Squeezing condition \\
\hline $0+600$ & 155 & 50 & 4 & 0.0008 & $0.02 \%$ & Few Support Problems \\
\hline $0+1400$ & 205 & 50 & 4 & 0.004 & $0.1 \%$ & Few Support Problems \\
\hline $0+2000$ & 590 & 40 & 4 & 0.25 & $6.25 \%$ & Very severe squeezing problems \\
\hline $0+2500$ & 345 & 40 & 4 & 0.23 & $5.75 \%$ & Very severe squeezing problems \\
\hline $0+3200$ & 145 & 30 & 4 & 0.14 & $3.5 \%$ & Severe squeezing problems \\
\hline
\end{tabular}

The results of assessment of squeezing using methods suggested by Singh et al. (1992) and Goel et al. (1994) are given in Table VII. The results based on semi-empirical method suggested by Hoek and Marinos (2000) is given in Table VIII.

\section{DESIGN OF SUPPORT SYSTEM}

\section{A. Support System Design Using Empirical Methods}

Support system for section at chainage $2+000$ was carried out using Q-system [8] and RMR [9] method. RMR system classifies the rock at this section as Poor rock while Q-system classifies it as very poor rock. The support suggested by these two methods are given in table below.

TABLE IX: SUPPORT SUGGESTED BY EMPIRICAL METHODS [8] [9]

\begin{tabular}{|c|c|c|}
\hline Method & RMR & Q-system \\
\hline Bolts & $\begin{array}{l}\text { End anchored, } 20 \mathrm{~mm} \\
\text { diameter, systematic bolts } \\
4-5 \mathrm{~m} \text { long, spaced } 1-1.5 \mathrm{~m} \\
\text { in crown and walls with } \\
\text { wire mesh. }\end{array}$ & $\begin{array}{l}25 \mathrm{~mm} \text { diameter, } \\
2.5 \mathrm{~m} \text { long grouted } \\
\text { rock bolts@1.3x } \\
1.5 \mathrm{~m} \text { spacing. }\end{array}$ \\
\hline Shotcrete & $\begin{array}{l}100-150 \mathrm{~mm} \text { in crown and } \\
100 \mathrm{~mm} \text { in sides. }\end{array}$ & $\begin{array}{l}10 \mathrm{~cm} \text { thick steel } \\
\text { fibre reinforced } \\
\text { shotcrete }\end{array}$ \\
\hline Steel Sets & $\begin{array}{l}\text { Light to medium ribs } \\
\text { spaced } 1.5 \mathrm{~m} \text { where } \\
\text { required. }\end{array}$ & None \\
\hline
\end{tabular}

\section{B. Support System Design Using Analytical Method}

Convergence confinement method was used for analytical design of the support system. Carranza, Torres and Fairhurst put forward three terms in CCM [10].

\section{Longitudinal displacement profile}

LDP represents the graph of the radial displacement that occurs along the axis of a cylindrical tunnel for sections ahead and behind the excavation face. Vlachopoulos and Diederichs in 2009 proposed a set of best fit relationships [11], and those equations have been used in this study for construction of GRC and LDP.

\section{Ground Reaction Curve}

GRC is the graphical representation of decreasing internal pressure plotted against increasing radial displacement of tunnel wall. This relationship is obtained from the elastoplastic solution of deformation of rock around an excavation.

\section{Support Characteristics Curve}

SCC is the relationship between stress on the support and the radial displacement of the support.

\section{Calculation of support strength:}

\section{Shotcrete lining:}

The maximum support that is provided by shotcrete lining can be calculated by the using the theory of hollow cylinders.

$$
\mathrm{p}_{\mathrm{s}}^{\max }=\frac{\sigma_{\mathrm{cc}}}{2}\left[1-\frac{\left(\mathrm{R}-\mathrm{t}_{\mathrm{c}}\right)^{2}}{\mathrm{R}^{2}}\right]
$$

The stiffness constant $\mathrm{K}_{\mathrm{s}}$ is as follows:

$$
\mathrm{K}_{\mathrm{s}}=\frac{\mathrm{E}_{\mathrm{c}}}{\left(1-\mathrm{v}_{\mathrm{C}}\right) \mathrm{R}} \frac{\mathrm{R}^{2}-\left(\mathrm{R}-\mathrm{t}_{\mathrm{c}}\right)^{2}}{\left(1-\mathrm{v}_{\mathrm{C}}\right) \mathrm{R}^{2}+\left(\mathrm{R}-\mathrm{t}_{\mathrm{c}}\right)^{2}}
$$

Where,

$\mathrm{E}_{\mathrm{c}}$ elastic modulus of concrete,

$v_{c}$ is Poisson's ratio,

$\mathrm{R}$ is external radius of tunnel (m),

$t_{c}$ is thickness of the concrete or shotcrete, and

$\sigma_{\mathrm{cc}}$ is unconfined compressive strength of the shotcrete or concrete

\section{Rock Bolts:}

If the circumferential spacing of the bolts are assumed to be equal, the maximum support provided by rock bolts is given by:

$$
\mathrm{p}_{\mathrm{s}}^{\max }=\frac{\mathrm{T}_{\mathrm{bf}}}{\mathrm{s}_{\mathrm{c}} \mathrm{s}_{\mathrm{l}}}
$$

And the stiffness is given by:

$$
\frac{1}{\mathrm{~K}_{\mathrm{s}}}=\mathrm{s}_{\mathrm{c}} \mathrm{s}_{\mathrm{l}}\left[\frac{4 \mathrm{l}}{\pi \mathrm{d}_{\mathrm{b}} \mathrm{E}_{\mathrm{s}}}+Q\right]
$$

Where,

$\mathrm{d}_{\mathrm{b}}$ is the bolt or cable diameter $(\mathrm{m})$,

1 is the free length of bolt or cable $(\mathrm{m})$,

$\mathrm{T}_{\mathrm{bf}}$ is the ultimate load obtained from a pull-out test (MN),

$\mathrm{Q}$ is a deformation load constant for the anchor and head (m/MN),

$E_{s}$ is Young's modulus of bolt or cable $(\mathrm{MPa})$,

$\mathrm{S}_{\mathrm{c}}$ is the circumferential bolt spacing $(\mathrm{m})$, and

$\mathrm{S}_{\mathrm{l}}$ is the longitudinal bolt spacing $(\mathrm{m})$

\section{Steel Sets:}

The maximum support pressure of the set is: 


$$
\mathrm{p}_{\mathrm{s}}^{\max }=\frac{\mathrm{A}_{\mathrm{s}} \sigma_{\mathrm{y}}}{\mathrm{s}_{\mathrm{c}} \mathrm{R}}
$$

And the stiffness is:

$$
\mathrm{K}=\frac{\mathrm{E}}{\mathrm{SR}^{2}}
$$

Where,

$\sigma_{\mathrm{ys}}$ is yield strength of steel (MPa),

$\mathrm{E}_{\mathrm{s}}$ is the Young's modulus of the steel ( $\left.\mathrm{MPa}\right)$,

$\mathrm{A}_{\mathrm{s}}$ is the cross-sectional area of the section (m),

$\mathrm{S}_{1}$ is the set spacing along the tunnel axis $(\mathrm{m})$, and

$\mathrm{R}$ is the radius of the tunnel (m)

\section{Combined system:}

In this case, the stiffness of the combined system is determined as the sum of the stiffness of the individual components.

$$
\mathrm{K}=\mathrm{K}_{1}+\mathrm{K}_{2}
$$

Where, $\mathrm{K}_{1}=$ stiffness of the first system, and $\mathrm{K}_{2}=$ stiffness of the second system.

The GRC, LDP and SCC were prepared for the section $2+000$ and by providing $150 \mathrm{~mm}$ Shotcrete of UCS $25 \mathrm{Mpa}$, End anchored Rock Bolts $25 \mathrm{~mm}$ diameter and $2.5 \mathrm{~m}$ long, a FOS of 2.33 was obtained.

TABLE X: Characteristic Properties OF SUPPORT SySTEM

\begin{tabular}{|l|l|}
\hline Combined elastic stiffness $\left(\mathrm{K}_{\mathrm{sb}}\right)$ & $1561.63 \mathrm{MPa} / \mathrm{m}$ \\
\hline Maximum displacement $\left(\mathrm{u}_{\mathrm{r}}\right)$ & $0.0015 \mathrm{~m}$ \\
\hline $\begin{array}{l}\text { Maximum support pressure } \\
\left(\mathrm{P}_{\text {sbmx }}\right)\end{array}$ & $2.311 \mathrm{MPa}$ \\
\hline
\end{tabular}

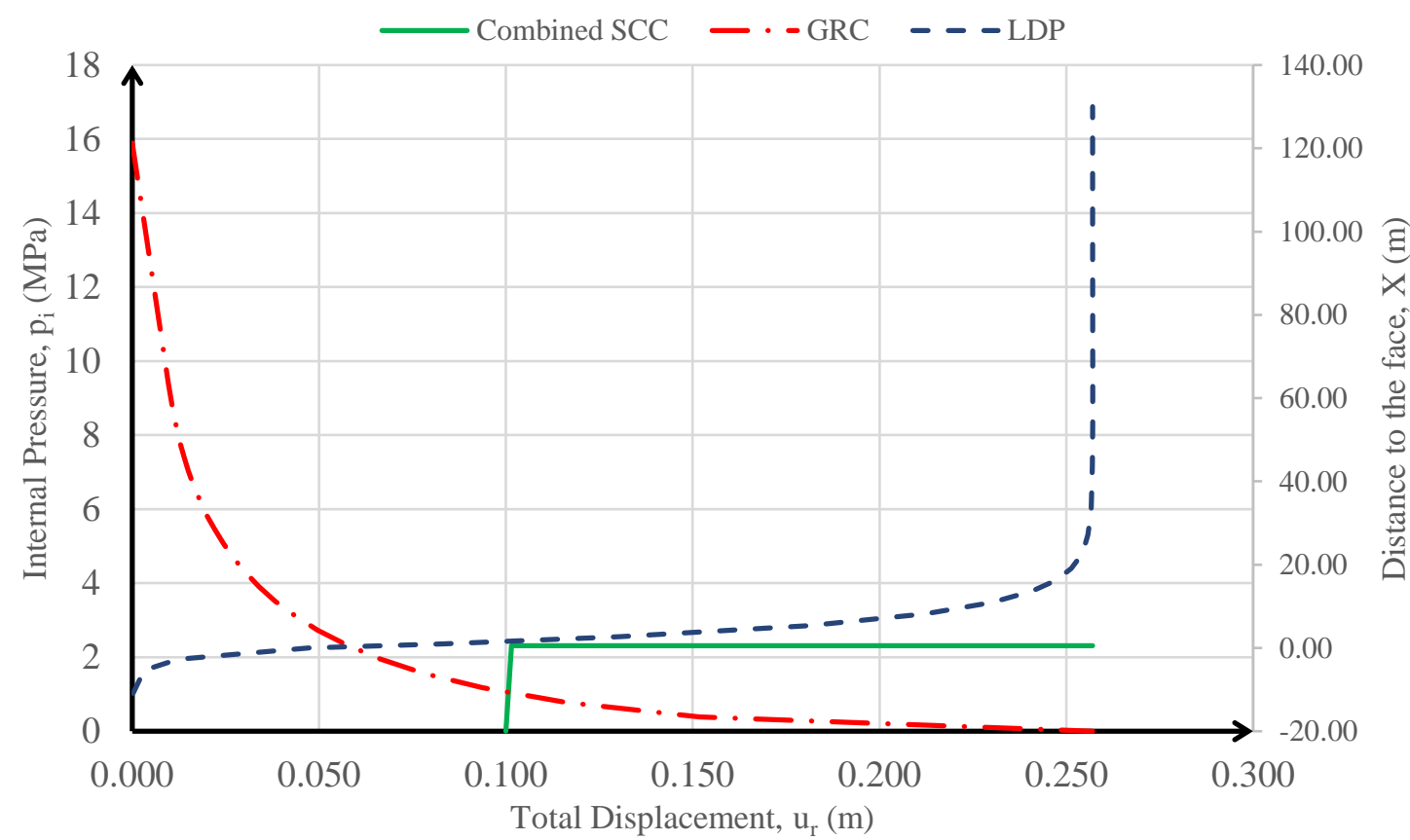

FIGURE III: GRC, LDP AND SCC FOR SECTION 2+000

\section{Two-dimensional Numerical Modelling using Phase ${ }^{2}$}

Finite Element Method is the most widely employed numerical method for rock mechanics and rock engineering. It does not require detailed programming experience to make efficient use of the finite element approach to problem solving in rock mechanics. However, familiarity with the fundamentals of the technique and with practical guidelines for generating reliable results is essential not only for the preparation of the program input, but also for recognition of faulty output.

The Phase $^{2}$ [12] is a 2-dimensional FEM based program and is very popular for the analysis of underground/surface excavation in rock mass or soil. In this research, the support system for tunnel section at chainage $2+000$ is also carried out using two-dimensional Numerical Modelling.
TABLE XI: INPUT PARAMETERS FOR TWO-DIMENSIONAL NUMERICAL MODELLING

\begin{tabular}{|c|c|}
\hline Rock Mass Property & Values \\
\hline Rock Type & Schist \\
\hline Poisson's Ratio & 0.1 \\
\hline$\sigma_{\mathrm{ci}}(\mathrm{MPa})$ & 40 \\
\hline $\mathrm{m}_{\mathrm{i}}$ & 10 \\
\hline $\mathrm{GSI}$ & 35 \\
\hline $\mathrm{D}$ & 0.5 \\
\hline $\mathrm{E}_{\mathrm{i}}(\mathrm{MPa})$ & 34000 \\
\hline $\mathrm{m}_{\mathrm{b}}$ & 0.453 \\
\hline $\mathrm{s}$ & 0.0001722 \\
\hline $\mathrm{a}$ & 0.5159 \\
\hline Unit Weight $\left(\mathrm{KN} / \mathrm{m}^{3}\right)$ & 27 \\
\hline Overburden $(\mathrm{m})$ & 590 \\
\hline
\end{tabular}


Hoek and Brown criterion was used to carry out nonlinear analysis. The Hoek-Brown constant are determined as follows:

$$
\begin{gathered}
\mathrm{m}_{\mathrm{b}}=\mathrm{m}_{\mathrm{i}} \exp \left(\frac{\mathrm{GSI}-100}{28-14 \mathrm{D}}\right) \\
\mathrm{s}=\exp \left(\frac{\mathrm{GSI}-100}{9-3 \mathrm{D}}\right) \\
\mathrm{a}=\frac{1}{2}+\frac{1}{6}\left(\mathrm{e}^{-\mathrm{GSI} / 15}-\mathrm{e}^{-20 / 3}\right)
\end{gathered}
$$

The total closure of the tunnel in unsupported condition was found to be $0.216 \mathrm{~m}$. The radius of plastic zone was $9.02 \mathrm{~m}$. The ratio of distance from tunnel face to tunnel radius $(\mathrm{X} / \mathrm{Rt})$ was 2 and plastic zone to tunnel radius (Rt/Rp) was 4.51 . Vlachopoulos and Diederichs method was used to determine the ratio of closure to maximum closure which was found to be 0.44 . Therefore, the closure equaled $0.096 \mathrm{~m}$. This was about $44 \%$ of the total closure of $0.216 \mathrm{~m}$. This meant that $44 \%$ of deformation will already have taken place before the support can be installed. An Internal pressure factor of 0.02 yield the tunnel wall displacement computed above for the point of support installation.

The support system used in numerical modelling is given in Table XII.

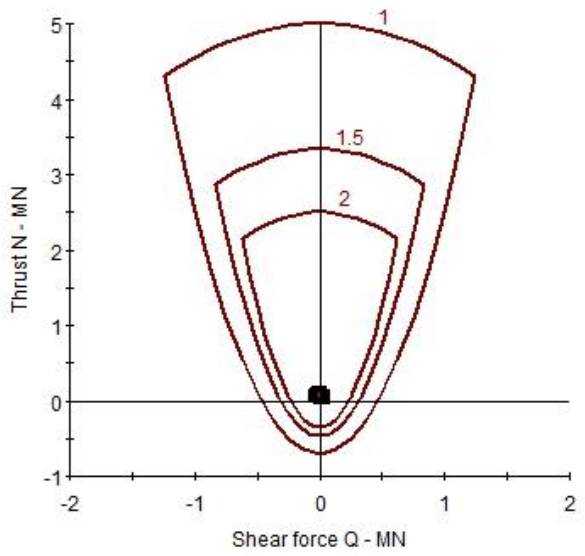

TABLE XII: SUPPORT ANALYSED USING TwO-DIMENSIONAL NUMERICAL

\begin{tabular}{|l|l|l|l|}
\hline \multicolumn{3}{|c|}{ Rock Bolts } & \multicolumn{2}{c|}{ Shotcrete } \\
\hline Type & $\begin{array}{l}\text { End } \\
\text { Anchored }\end{array}$ & UCS & $25 \mathrm{Mpa}$ \\
\hline Length & $2.5 \mathrm{~m}$ & $\begin{array}{l}\text { Youngs } \\
\text { Modulus }\end{array}$ & $25000 \mathrm{MPa}$ \\
\hline Diameter & $25 \mathrm{~mm}$ & $\begin{array}{l}\text { Thickness } \\
\text { of shotcrete }\end{array}$ & $200 \mathrm{~mm}$ \\
\hline Bolt Modulus & $\begin{array}{l}2 \times 10^{5} \\
\mathrm{MPa}\end{array}$ & $\begin{array}{l}\text { Poisson's } \\
\text { Ratio }\end{array}$ & 0.2 \\
\hline $\begin{array}{l}\text { Out of Plane } \\
\text { Spacing }\end{array}$ & $1.5 \mathrm{~m}$ & $\begin{array}{l}\text { Tensile } \\
\text { Strength }\end{array}$ & $3.5 \mathrm{MPa}$ \\
\hline
\end{tabular}

For factor of safety of 1.0,1.5 and 2.0, safety envelopes of axial force vs moment space and axial force vs shear force space were generated. It can be seen from Figure IV that the values of axial force, moment and shear force in the liners, when compared to the capacity envelope, lie inside the curve of FOS of 2.0. Also, there was no yielding in the rock bolts and lines which can be seen in Figure V.

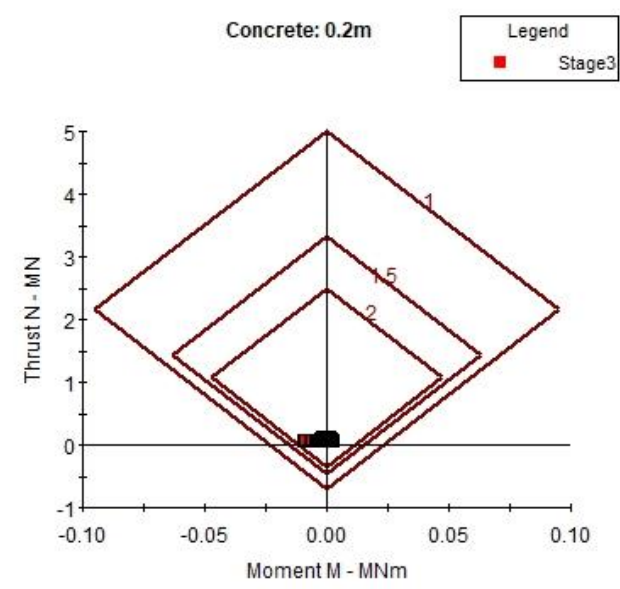

Support Element: Shotcrete

FIGURE IV: SAFETY ENVELOPE FOR FOS 1, 1.5 AND 2.0

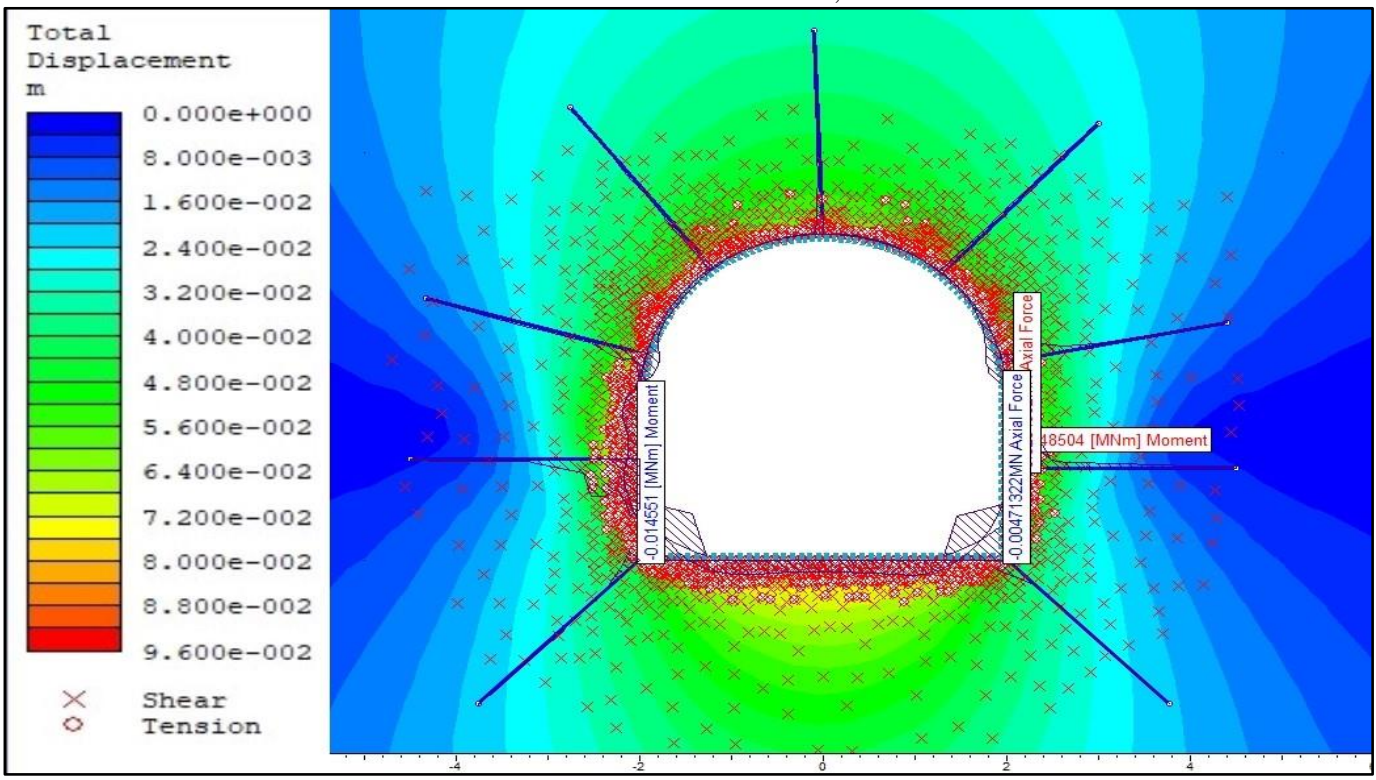

Figure V: TOTAL DisPLACEMENT AROUND TUNNEL with SUPPORT AND FORCES ON LINER AND BOLTS 


\section{Three-Dimensional Modelling using GTS-NX}

Like any numerical modeling, three-dimensional modeling requires a control volume in which analysis is to be made. But in case of 3D-modeling a control volume with all three dimensions has to be selected. Keeping in mind the solution of a circular hole on a metal plate given by Kirsch, it is known that in case of elastic bodies the stress due to excavation dies out at a distance of 3-5 from the center of excavation. But the rock masses in which the tunnel under consideration is being excavated shows elasto-plastic nature so, plastic zone has to be considered. Hence, geometric model with control volume of dimensions ten to twenty times that of tunnel diameter was created for analysis in this research work.

GTS-NX [13] was used to carry out three-dimensional analysis on selected zones where the longitudinal homogeneity of the tunnel breaks due to presence of additional excavations. One of such three-dimensional design of support system for the headrace tunnel - surge shaft junction is presented in this paper.

The geometric model was prepared considering the symmetry plane passing vertically through the axis of the main tunnel. The material model is restricted in translation at the four faces in the sides along the direction perpendicular to those faces and is restricted for translation along all three axes at the bottom face. The upper face of the model is free to move in all three direction.

This analysis is carried out using a non-linear analysis based on Generalized Hoek-Brown criterion. The tolerance is kept at 0.001 for load and 1e-06 for work done. NewtonRaphson method was used to solve the non-linear equations at created nodes. Tunnel closure was found to be $30 \mathrm{~mm}$.

Figure VI shows the maximum shear stress imposed on the shotcrete lining. The stress is maximum at the junction of the surge shaft with the main tunnel. This stress has increased from top to bottom of the surge shaft as the vertical in-situ stress goes on increasing. The maximum shear strength of shotcrete of $100 \mathrm{~mm}$ thickness for a tunnel radius diameter of $4 \mathrm{~m}$ is $1.219 \mathrm{MPa}$, obtained by using properties of hollow cylinder. Here, the maximum shear stress induced is 0.511 $\mathrm{MPa}$. This gives a minimum factor of safety of 2.38 at the junction. Since, the factor of safety is above two, this can be considered safe.

TABLE XIII: SuPPORT SySTEM ANALYSED USING THREE-DIMENSIONAL MODELLING

\begin{tabular}{|c|c|c|c|c|}
\hline \multicolumn{3}{|c|}{ Rock Bolts } & \multicolumn{2}{|c|}{ Shotcrete } \\
\hline \multicolumn{2}{|c|}{ Type, Model } & 1D, Embedded Truss & Type, Model & 2D, Shell \\
\hline \multirow{2}{*}{ Length } & In Main-Tunnel & $2.5 \mathrm{~m}$ & Poisson's Ratio & 0.2 \\
\hline & In Surge Shaft & $4 \mathrm{~m}$ & Compressive Strength & $25 \mathrm{MPa}$ \\
\hline \multicolumn{2}{|c|}{ Poisson's Ratio } & 0.25 & Tensile Strength & $3.5 \mathrm{MPa}$ \\
\hline \multicolumn{2}{|c|}{ Spacing (In-plane, Out of plane) } & $1 \mathrm{~m}, 1.5 \mathrm{~m}$ & Thickness & $0.1 \mathrm{~m}$ \\
\hline \multicolumn{2}{|c|}{ Section Shape } & Solid Round & Young's Modulus & $25000 \mathrm{MPa}$ \\
\hline \multicolumn{2}{|c|}{ Diameter } & $0.025 \mathrm{~m}$ & Unit Weight & $24 \mathrm{KN} / \mathrm{m}^{3}$ \\
\hline \multicolumn{2}{|c|}{ Tensile capacity } & $0.1 \mathrm{MN}$ & & \\
\hline \multicolumn{2}{|c|}{ Bolt Modulus } & $200000 \mathrm{MPa}$ & & \\
\hline
\end{tabular}




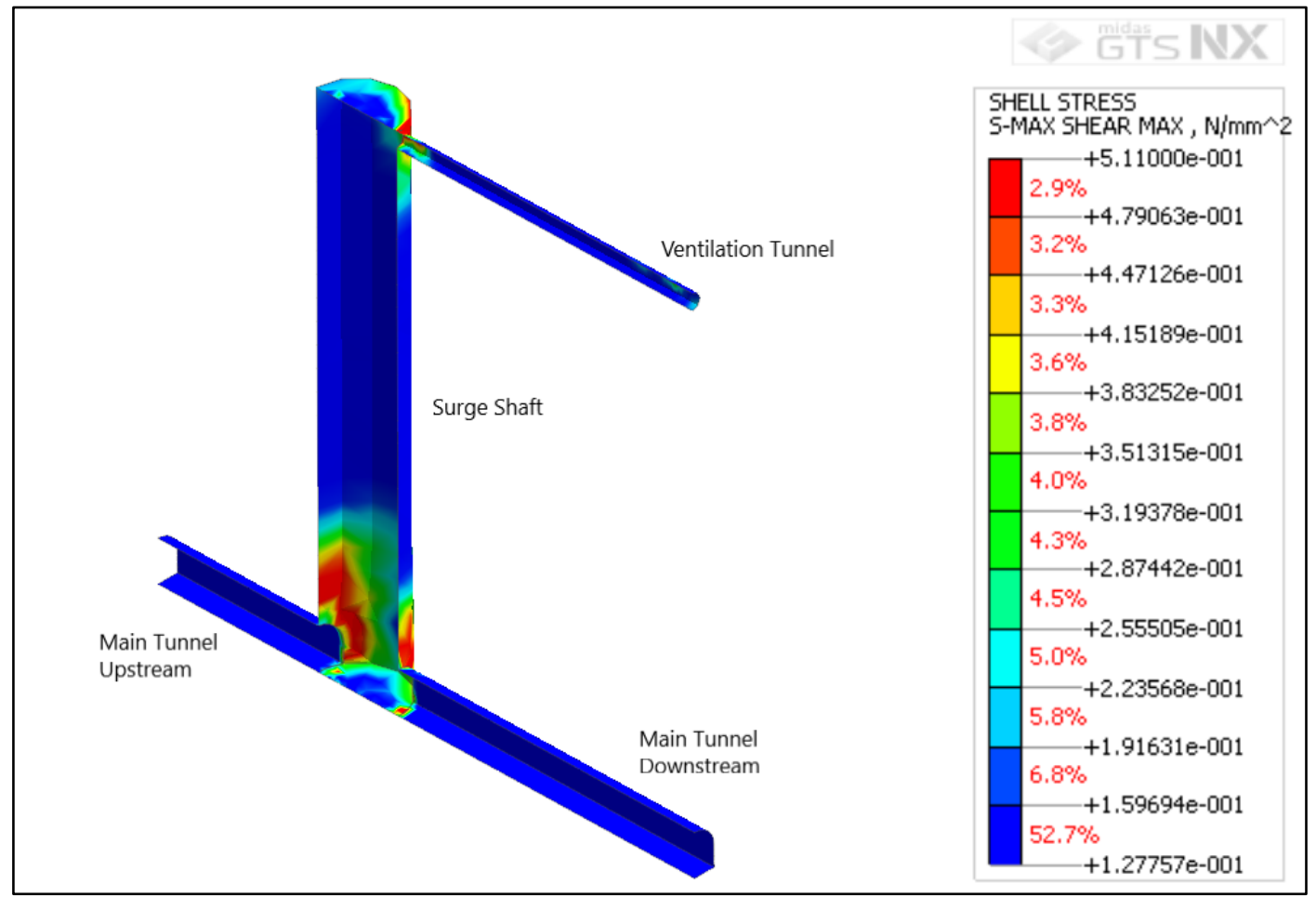

Figure VI: Maximum SheAr Stress in SHotcrete Around Surge SHAFT

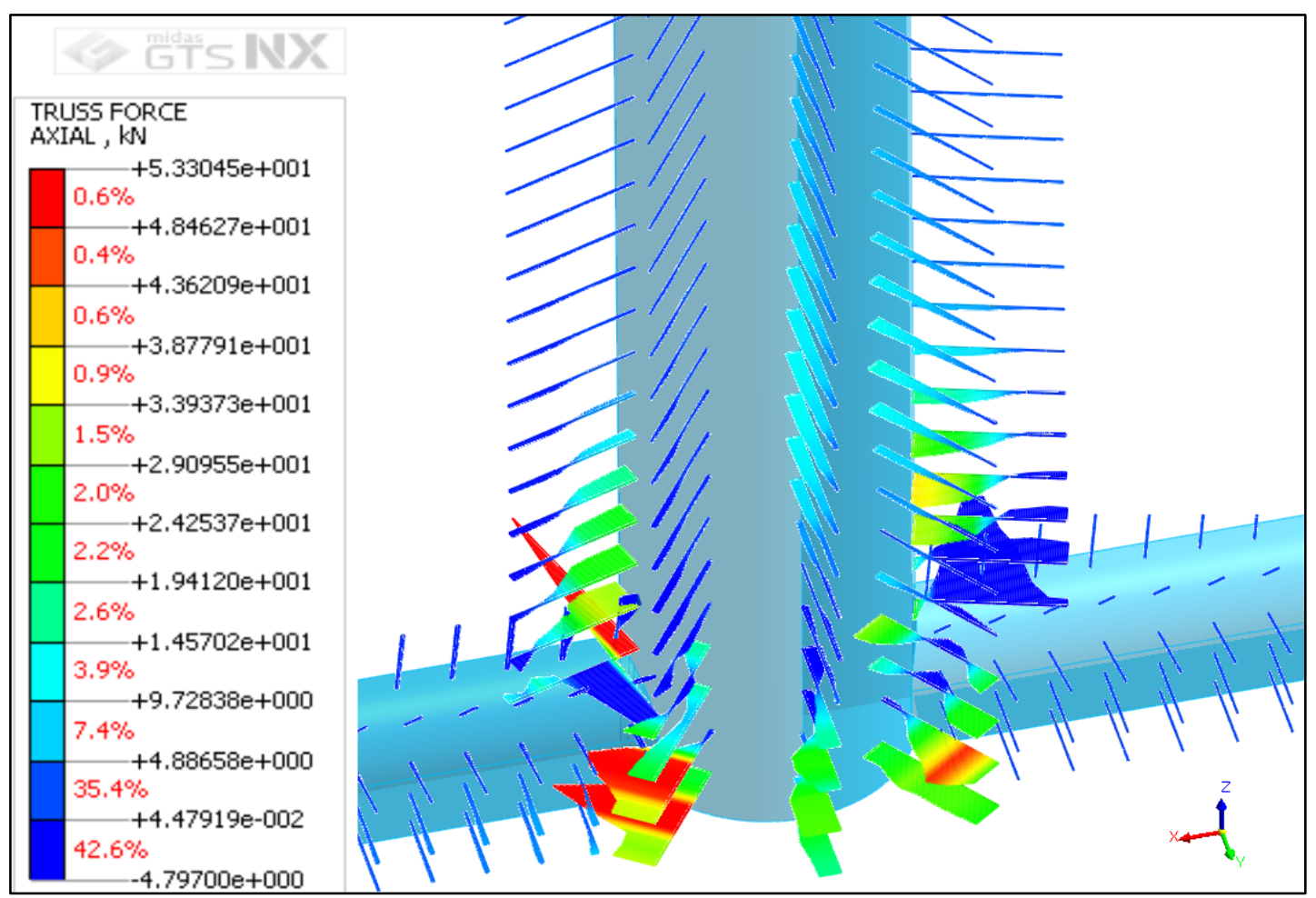

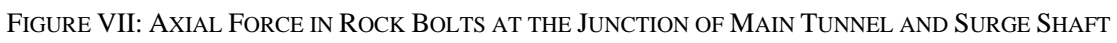

Figure VII shows the axial force in the rock bolts in the periphery of the surge shaft. Here, it can be seen that the axial force is maximum at the junction of Main Tunnel with the Surge Shaft, near the flat invert of the tunnel.

The maximum tensile capacity of the bolt used is $0.1 \mathrm{MN}$, i.e. $100 \mathrm{KN}$. The maximum axial force induced in the Rock Bolt here is $53.3 \mathrm{KN}$. This gives factor of safety of 1.87 at the junction. Considering the junction is lined using concrete panel, this value of safety factor is safe.

\section{CONCLUSIONS}

In this study, rock mass classification, prediction of rock burst and prediction of squeezing was assessed at five different sections along the $4 \mathrm{~m}$ diameter D-shaped headrace tunnel of Upper Balephi 'A' hydropower in Sindhupalchowk, Nepal. 
Support system was designed for a section at chainage $2+000$ using empirical, analytical and two-dimensional numerical modeling. Three-dimensional modeling was used to predict the support required at the junction of the tunnel with an underground vertical surge shaft of diameter $8 \mathrm{~m}$. Upon comparison with criteria suggested by various researchers, it was found that even though the rock mass at the first two sections were hard rocks types shown by the high RMR value, they were stable against Rock Burst. But the sections at chainage 2+000 and 2+500 were found to possess chances og rock bursting. The Hoek and Brown approach suggested requirement of heavy support at the wall in section $2+000$ while minor wall spalling in section $1+400,2+500$ and $3+200$. This is mostly due to the D-shape of the tunnel as there will be high stress induced at the corners in the invert level. The Grimstad and Barton method suggested that at section $2+500$, the stress is very high which is usually favorable for overall stability but that it can be unfavorable for wall stability. Again, this is due to the high stress induced at the corners of the invert. It also suggested that in the wall of the section $2+000$, slabbing and rock burst will occur after minutes in case of massive rocks. The empirical and semi-empirical methods suggested that there will be no squeezing at the first two sections. However, it was found that there is probability of squeezing in three sections at chainage $0+2000,2+500$ and $3+200 \mathrm{~m}$, which were also found to be susceptible to rock burst. But since the rock type is weak at these three sections, squeezing poseses the major threat rather than rock burst. For further analysis, detailed study will be required with subsurface drilling data. So, while providing supports, precautions against squeezing should be taken at the later three sections. Two-dimensional analysis is sufficient for analysis of stress distribution and design of support system in sections where plain strain conditions can be assumed like in section $2+000$, but in places where the longitudinal symmetry breaks and stress varies along the longitudinal direction, only three-dimensional approach can give accurate results. Most of the designs today involving tunnel junctions with adit, with surge shaft or in cases of bends in the tunnel are made using empirical methods assuming conservative design with high factor of safety. But this might turn out to be uneconomical and three-dimensional modelling can give the most accurate estimation in such cases as shown in this study.

\section{ACKNOWLEDGMENT}

The authors are thankful to Department of Civil Engineering, Institute of Engineering, Tribhuvan University for providing the opportunity to carry out this study. The author wishes to acknowledge M.Sc. Program Co-ordinator Associate Professor Dr. Indra Prasad Acharya for his invaluable suggestions and encouragement during the research. The authors are obliged to all colleagues, family and friends who helped in this study.

\section{REFERENCES}

[1] "Report on Rock Support Analysis of Underground Excavation," Kathmandu, Nepal, 2017.

[2] Hoek and Brown, Underground Excavation in rock, Institution of Mining and Metallurgy, 1980

[3] E. Grimstad and N. Barton, "Updating the Q-system for NMT," Proceedings of the international symposium on sprayed concrete, Norwegian concrete assosiation, Oslo, Norway, 1993.

[4] B. Singh, J. L. Jethwa and A. K. Dube, "Correlation between Observed Support Pressure and Rock Mass Quantity," Tunnelling and Underground Space Technology, 1992.

[5] R. K. Goel, J. L. Jethwa and A. G. Paithankar, "Indian Experiences with Q and RMR Systems," Tunneling and Underground Space Technology, 1995.

[6] E. Hoek and P. Marinos, "Predicting tunnel squeezing problems in weak heterogeneous rock masses," Tunnels and Tunnelling International, 2000

[7] S. Sakurai, "Displacement measurements associated with the design of underground openings," Proc. Int. Symp. Field Measurements in Geomechanics., 1983.

[8] N. Barton and E. Grimstad, "Forty years with the Q-system in Norway and Abroad," GEOTEKNIKK, 2014.

[9] Kaisier et al., Evaluation of rock classification at B.C Rail tumbler ridge tunnels., Rock Mechanics and Rock Engineering, 1986.

[10] Carranza, Torres and Fairhust, "Application of the convergenceconfinement method of tunnel design to rock masses that satisfy the Hoek-Brown failure criterion," Tunneling and Underground Space Technology, pp. 187-213, 2000.

[11] N. Vlachopoulos and M. Diederichs, "Improved Longitudnal Displacement Profiles for Convergence Confinment Analysis of Deep Tunnels," Rock Mechanics and Rock Engineering, 2009.

[12] R. Inc., "Phase2 model program reference manual," [Online]. Available: https://www.rocscience.com/downloads/phase2/Phase2_ModelRefer ence.pdf.

[13] "Product Announcement GTS NX 2019 (v2.1)," Midas IT Co. Ltd., 2019. [Online]. Available: https://www.midasgeotech.com/blog/new_release_of_midas_gtsnx 2019v2.1\#none. 